Analy lica Chimica Acia. 90 (1977) 61-69

C Elsevier Scieritific Publishing Company, Amsterdam - Printed in The Netherlands

\title{
AN ONLINE COMPUTER METHOD FOR THE POTENTIOMETRIC TITRATION OF MIXTURES OF A STRONG AND A WEAK ACID
}

\author{
M. BOS \\ Department of Chemical Technology, Twente Universily of Technology, Enschede \\ (The Netherlonds)
}

(Received 9th November 1976)

\section{SUMMARY}

A PDP-11 online computer method for the titration of mixtures of a strong and a weak acid is described. The method is based on multiparametric curve-fitting. One of the parameters found from the calculations is the dissociation constant of the weak acid, hence the method can be applied even when this constant is unknown. Accurate results (relative error $\pm 1 \%$ ) were obtained for weak acids $w$ ith $\mathrm{ph}_{\mathrm{a}}$ values or $0.2-10$. A complete titration and calculation takes about $20 \mathrm{~min}$.

Almost any mixture of a strong and a weak acid can be resolved by the use of nonaqueous titrations, but in the more frequently encountered case of aqueous samples, the water in the sample nullifies the effect of the nonaqueous solvent.

Differential potentiometric titrations of a mixture of a strong and a weak acid in aqueous solution can give rise to problems in two situations: (a) when the weak acid has a low $\mathrm{p} K$, value, normal acid-base titration methods give only the total amount of acid present; (b) when the weak acid has a very high $\mathrm{p} K_{\mathrm{a}}$ value, it cannot be titrated, and only the strong acid can be determined.

Several authors have already developed procedures for the evaluation of poorly defined potentiometric titration curves in which the end-points cannot be located straightforwardly from the inflection points. McCailum and Midgley [1] described a method for the titration of mixtures of strong and weak acids based on linearization of the titration curve. However, the exact value of the dissociation constant of the weak acid must be known, and this precludes the use of the method when the nature of the weak acid is unknown.

Multiparametric curve-fitting seems to be a more promising technique. Its success in titrimetric analysis has been demonstrated by Meites et al. [2-5] and by Ingman et al [6]. These authors used generalized multiparametric curve-fitting computer programs which require iittle extra programming effort for adaptation to various titration problems but are rather slow. Ingman et al. [6] also used generalized expressions for the titration equation. This makes their method very versatile, but very difficult to implement 
online in a minicomputer because of the large program size and the length of the calculations when the dissociation constants of the titrated species are unknown.

The practical usefulness of an analytical method depends to a great extent on the time needed to produce the result. In the design of a computerized analytical method this means online data acquisition and evaluation of the result in a fraction of the time needed to complete the experiment. The latter is of prime importance when the method has to be operated in a multiuser computer environment. It has been shown [7] that the Wentworth multiparametric curve-fiting method [8] is very suitable for obtaining high calculation speeds. This paper describes how the Wentworth method can be used to provide a rapid and fully computerized titration of mixtures of a strong and a weak acid. Three parameters from the charge balance equations for the titration points are adjusted to obtain a least-squares fit: the concentration of the strong acid, the concentration of the weak acid and the dissociation constant of the weak acid.

\section{THEORY}

The symbols used are defined in Table 1.

Charge ba!ance equation for the titration of a mixture of a strong acid $H X$ and a weak acid $H Y$ with sodium hydroxide

The charge balance equation for each point of the titration curve is given by

$m_{\mathrm{H}^{+}}+m_{\mathrm{Na}^{*}}-m_{\mathrm{X}^{-}}-m_{\mathrm{Y}^{-}}-m_{\mathrm{OH}^{-}}=0$

This equation can be combined with the dissociation equilibrium equations for water and the weak acid

$K_{\mathrm{HY}}=\frac{a_{\mathrm{H}} \cdot a_{Y}}{a_{\mathrm{HY}}}$

TABLE 1

\begin{tabular}{|c|c|c|c|}
\hline \multicolumn{4}{|c|}{ Glossary of symbols } \\
\hline $\begin{array}{l}\mathrm{HX} \\
\mathrm{HY} \\
g \\
K_{H Y} \\
K_{W} \\
f^{\prime} \\
V^{r} \\
T\end{array}$ & $\begin{array}{l}\text { strong acid } \\
\text { weak acid } \\
\text { activity } \\
\text { dissociation constant of weak acid } \\
\text { disscciation constant of ivater } \\
\text { activity coefricient } \\
\text { volume oi NaOH atded } \\
\text { volume at start of titration } \\
\text { iter of } \mathrm{NaOH}\end{array}$ & $\begin{array}{l}c_{\mathrm{HX}} \\
C_{\mathrm{HY}} \\
F_{i} \\
\mathrm{~m}^{0}:-\mathrm{HX} \\
C^{0} \mathrm{HY} \\
K_{\mathrm{HY}}^{\mathrm{g}}\end{array}$ & $\begin{array}{l}\text { stoichiometric concentration of } \\
\text { strong acid at start of titration } \\
\text { stoichiometric concentration of } \\
\text { weak acid at starl of titration } \\
\text { function relating } c_{\mathrm{H}^{+}} \text {and } V \\
\text { during the titration } \\
\text { concentration } \\
\text { initial estimate of } C_{\mathrm{HX}} \\
\text { - initia! estimate of } C_{\mathrm{HY}} \\
\text { initial estimate of } K_{\mathrm{HY}}\end{array}$ \\
\hline
\end{tabular}


and

$K_{\mathrm{W}}=a_{\mathrm{H}^{+}} \cdot a_{\mathrm{OH}^{-}}$

to give

$F_{i}=0=\frac{a_{\mathrm{H}^{+}}}{f_{\mathrm{H}^{+}}}+\frac{V \cdot T}{V+V_{0}}-\frac{C_{\mathrm{HX}} V_{0}}{V+V_{0}}-\frac{C_{\mathrm{HY}} \cdot K_{\mathrm{HY}} \cdot V_{0}}{\left(a_{\mathrm{H}^{*}} \cdot f_{\mathrm{Y}^{-}}+K_{\mathrm{HY}}\right)\left(V+V_{0}\right)}-\frac{\check{K}_{\mathrm{W}}}{a_{\mathrm{H}^{+}} \cdot f_{\mathrm{OH}^{-}}}$

This equation holds for each point of the titration curve, i.e. for the complete set of $a_{\mathrm{H}^{+}} / V$ combinations.

The multipgrametric curve-fitting procedure for the titration data

The experimental data set comprising the titration curve consists of $n$ pairs of observations of $a_{\mathrm{HI}}$ + values versus ml of titrant, designated by

$\left(a_{\mathrm{H}}, V_{i}\right) \quad i=1,2, \ldots, n$

Equation (4) relates the two variables $a_{\mathrm{H}}$, and $V_{i}$. This equation contains a large number of parameters, viz. $f_{\mathrm{H}^{*}}, V_{\mathrm{O}}, T, C_{\mathrm{HX}}, C_{\mathrm{HY}}, K_{\mathrm{HY}^{\prime}}, f_{\mathrm{Y}^{-}}, K_{\mathrm{W}}$ and $f_{\mathrm{OH}}$-. Least-squares estimates are wanted for the parameters $C_{\mathrm{HX}}, C_{\mathrm{HY}}$ and $K_{\mathrm{HY}}$.

The paraneters $K_{\mathrm{W}}, T$ and $V_{0}$ are known previously. The activity coefficients $f_{\mathrm{H}}, f_{\mathrm{Y}^{-}}$and $f_{\mathrm{OH}^{-}}$require some attention, because during normal titrations their values change.

If they can be treated as constants ior the whole titration curve, calculations are simplified greatly. This can be accomplished by adding an excess of inert salt, which minimizes changes in the ionic strength during the titration. In this work $1 \mathrm{M}$ potassium chloride was chosen, mainly because of the availability of data on activity coefficients of some compounds in its presence [9].

For $1 \mathrm{M}$ potassium chloride solutions the following data for activity coefficients and dissociation constants were used [9]

$K_{\mathrm{W}}=\frac{\left(f_{\mathrm{H}^{*}} \cdot f_{\mathrm{OH}^{-}}\right)\left(m_{\mathrm{H}} \cdot m_{\mathrm{OH}^{-}}\right)}{a_{\mathrm{H}, \mathrm{O}}}=6.81 \cdot 10^{-15} ; \frac{f_{\mathrm{H}^{-}} \cdot f_{\mathrm{OH}^{-}}}{a_{\mathrm{H}: \mathrm{O}}}=0.600$

Activity coefficient of hydrochloric acid [9] $f_{t}^{2}=f_{\mathrm{H}} \cdot \cdot f_{\mathrm{Cl}^{-}}=0.523$

Dissociation constant of acetic acid $[10,11]$

$K_{\mathrm{HAc}}=\frac{\left(f_{\mathrm{H}^{+}} \cdot f_{\mathrm{Ac}^{-}}\right)}{f_{\mathrm{HAC}}} \frac{\left(m_{\mathrm{HI}} \cdot m_{\mathrm{Ac}}\right)}{m_{\mathrm{HAC}}}=1.75 \cdot 10^{-5} ; \frac{f_{\mathrm{H}^{*}} \cdot f_{\mathrm{Ac}^{-}}}{f_{\mathrm{HAc}}}=0.562$

Activity coefficient $f_{=}$of $1 \mathrm{M} \mathrm{KCl}[12]: f_{:}^{2}=f_{\mathrm{K}} \cdot \cdot f_{\mathrm{Cl}^{-}}=0.365$.

If $f_{\mathrm{K}}$. is taken equal to $f_{\mathrm{Cr}}$ for the $1 \mathrm{M} \mathrm{KCl}$ solution then the following set of activity coefficients is consistent with the data in $1.1 \mathrm{KCl}$ mentioned above: 
$f_{\mathrm{H}^{*}}=0.87 ; f_{\mathrm{OH}^{-}}=0.68 ; f_{\mathrm{Ac}^{-}}=0.65 ; a_{\mathrm{H} ; \mathrm{O}}=0.99 ; f_{\mathrm{K}^{*}}=0.60 ; f_{\mathrm{CI}^{-}}=0.60$.

Least-squares adjustment of the parameters $C_{H X}, C_{K Y}$ and $K_{H Y}$ can be performed by the Wentworth [8] approach if partial derivatives of the function $F_{i}$ defined in eqn. (4) to these parameters and to $a_{H}$. and to $V$ are known. These partial derivatives are listed in the following equations

$$
\begin{aligned}
& \left(\frac{\delta F_{i}}{\delta V}\right)=\frac{T \cdot V_{0}}{\left(V+V_{0}\right)^{2}}+\frac{C_{H Y}^{0} \cdot K_{H Y}^{0}-V_{0}}{\left(a_{H^{+}} \cdot f_{Y^{-}}+K_{H Y}^{0}\right)\left(V_{0}+V\right)^{2}}+\frac{C_{H X}^{0} \cdot V_{0}}{\left(V_{0}+V\right)^{2}} \\
& \left(\frac{\delta \bar{F}_{i}}{\delta a_{\mathrm{H}^{*}}}\right)=\frac{1}{f_{\mathrm{H}^{*}}}+\frac{C_{\mathrm{HY}}^{\mathrm{O}} \cdot K_{\mathrm{HY}}^{\mathrm{O}} \cdot V_{\mathrm{O}} \cdot \hat{f Y}_{\mathrm{Y}^{-}}}{\left(V_{\mathrm{O}} \div V\left(a_{H^{*}} \cdot f_{\mathrm{Y}^{-}}+K_{\mathrm{HY}^{0}}\right)^{2}\right.} \div \frac{K_{\mathrm{W}}}{f_{\mathrm{OH}^{-}} \cdot\left(a_{H^{*}}\right)^{2}} \\
& \left(\frac{\delta F_{i}}{\delta C_{\mathrm{HX}}}\right)=-\frac{V_{\mathrm{o}}}{V_{\mathrm{o}}+V} \\
& \left(\frac{\delta F_{i}}{\delta C_{\mathrm{HY}}}\right)=-\frac{K_{\mathrm{HY}}^{\mathrm{O}} \cdot V_{\mathrm{O}}}{\left(a_{\mathrm{H}} \cdot f_{Y^{-}}+K_{\mathrm{HY}}^{\mathrm{o}}\right)\left(V_{\mathrm{O}}+V\right)} \\
& \left(\frac{\delta F_{i}}{\delta K_{\mathrm{HY}}}\right)=-\frac{C_{\mathrm{H}^{\circ}}^{0} \cdot V_{\mathrm{O}} \cdot a_{\mathrm{H}^{*}} \cdot f_{\mathrm{Y}^{-}}}{\left(\mathrm{a}_{\mathrm{H}} \cdot f_{\mathrm{Y}^{-}}+K_{\mathrm{HY}}^{0}\right)^{2}\left(V_{\mathrm{O}}+V\right)}
\end{aligned}
$$

\section{EXPERIMENTAL}

\section{Chemicals}

Except where specified, all chemicals were of analytical grade. Potassium chloride, sodium acetate, acetic acid (all Merck), ammonium chloride (Brocades), $m$-cresol (Baker 'PCS' reagent), urea and tris(hydroxymethyl)aminomethane (Fluka) were used as received.

Hydrochloric acid, suiphuric acid and sodium hydroxide solutions were prepared in $1 \mathrm{M}$ potassium chloride from Merck Titrisol ampoules by adding the calculated amount of potassium chioride and diluting to the specified volume with carbon dioxide-free double-distilled water. The sodium hydroxide solution was standardized coulometrically and used to standardize the solutions of hydrochloric acid, sulphuric acid and acetic acid. The titers of the ammonium chloride, $m$-cresol, scdium acetate and tris(hydroxymethyl)aminomethane solutions were calculated from the weight of compound added to a $1 \mathrm{M}$ potassium chloride solution. The urea solution was standardized by the Kjeldahl method.

\section{Equipment}

The automatic titration system consisted of the following items: 1DP-11/10 computer (Digital Equipment Corp.) with $16 \mathrm{~K}$ core memory, RKO5 disk, and the LPS laboratory peripheral system containing a 12 -bit $A / D$ converter and Teleprint telewriter; Mettler DV11 automatic burette; Knick industrial $\mathrm{pH}$-meter type DIN with Schott combined glass-calomel electrode type $\mathrm{N}$ 
with platinum wire diaphragm; Metrohm thermostatted titration vessel; Lauda ultra thermostat, type $43 / 58 / 12$. A schematic diagram of the system is given in Fig. 1.

\section{Procedures}

Calibration of the glass-calomel electrode set. Calibration of the electrode on stanciard NBS buffers (Electrofact) proved unsatisfactory, probably because of changes in liquid junction potential on transference to $1 \mathrm{M} \mathrm{KCl}$ solutions. To overcome this difficulty, solutions of known $\mathrm{pa}_{\mathrm{H}}$ * values were prepared in $1 \mathrm{M} \mathrm{KCl}$, viz. $0.1 \mathrm{M} \mathrm{HCl}, 0.1 \mathrm{M}$ acetic acid, $0.01 \mathrm{M}$ acetate buffer and $0.01 \mathrm{M} \mathrm{NaOH}$ with $\mathrm{pa}_{\mathrm{H}^{+}}$values $1.060,2.809,4.573$ and 12.000, respectively. These $\mathrm{pa} a_{\mathrm{H}}$, standards were used to obtain separate pa $a_{\mathrm{H}}$. calibration constants for the regions $\mathrm{pa} \mathrm{H}^{+}<3,3<\mathrm{pa} \mathrm{H}<8$ and $\mathrm{pa} \mathrm{H}^{+}>8$.

Titration of the samples. The sample is placed in the thermostatted $\left(20.0 \pm 0.1^{\circ} \mathrm{C}\right.$ ) titration vessel and $1 \mathrm{M} \mathrm{KCl}$ is added to give the starting volume required to the nearest $0.01 \mathrm{~mL}$. The electrodes are allowed to equilibrate for $5 \mathrm{~min}$, whereafter the titration with $0.1 \mathrm{M}$ sodium hydroxide in $1 \mathrm{M} \mathrm{KCl}$ is started by he computer. The titration is carried out in a nitrogen atmosphere. Normally $\mathrm{pa}_{\mathrm{H}}$. measurements are made at $0.100-\mathrm{ml}$ intervals of titrant addition, and after each addition 10 seconds are allowed, to attain equilibrium.

\section{Computer programs}

The sof tware for the automatic titration system was developed in four parts: (a) calibration of the glass electrode set; (b) control of the titration and recording of the titration curve; (c) the curve-fitting program; (d) a simple monitor for three real-time tasks and background facilities. The first two programs run as real-time tasks, whereas the curve-fitting program runs in the background during the recording of the next titration curve.

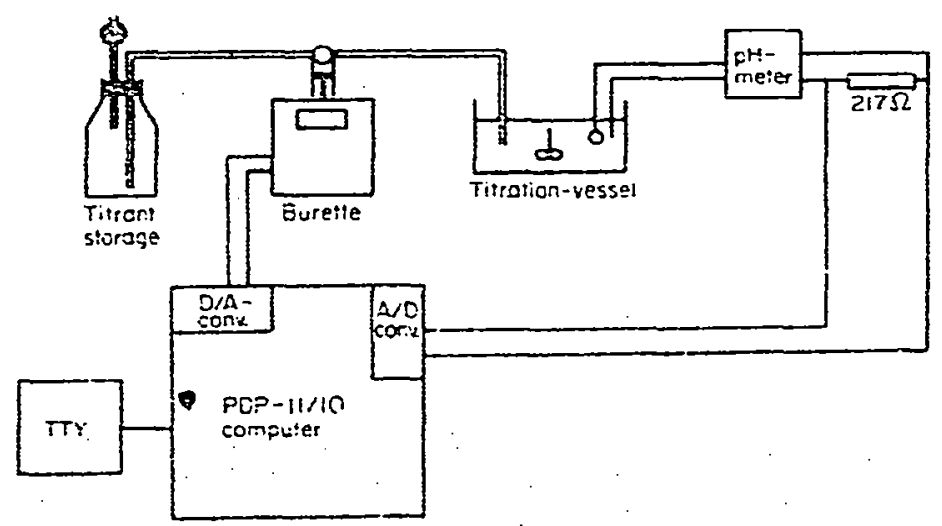

Fis. 1. Schematic diagram of automatic titration system. 
(a) The calioration program for the glass electrode. From e.m.f. measurements for a set of two buffers of known $\mathrm{po}_{\mathrm{H}^{*}}$, the slope and standard potential of the electrode set are calculated.

The input of the $\mathrm{pr}_{\mathrm{H}}$. values of the two buffers is done via the teletype, and the e.m.f. readings for the two buffers are taken by the $A / D$ converter of the LPS system connected to the $\mathrm{pH}$ meter. Output of the calculated alibration constants is to the teletype.

(b) The computer program for the titration. The program starts with a dialogue at the teletype in which the operator can set the various parameters that control the titration, viz. titrant addition per titration step, number of titration points, equilibration time per titration point and a sample identification. Then, alternately, $\mathrm{pH}$ readings are taken by the $\mathrm{A} / \mathrm{D}$ converter and a pulse train is generated to activate the stepmotor of the burette to deliver the required amount of titrant. This process is stopped when the required number of titration points has been reached. The program finishes with writing the acquired data in a disk file.

(c) The curve-fitting program. The e.m.f. data acquired by program (b) are converted to $p a_{H}$. vs. $m l$ data by means of the calibration constants from program (a).

Initial estimates for the parameters required, viz. concentration of strong acid, concentration of weak acid and the dissociation constant of the weak acid are obtained as follows. The concentration of the strong acid is taken as equal to the $a_{\mathrm{H}} \cdot / f_{\mathrm{H}}$. value at the start of the titration. The estimate of the total amount or acid is calculated from the volume of titrant needed to reach $\mathrm{pH}$ 11.0. From the estimate of the concentration of strong acid and the starting volume, the estimate for the concentration of weak acid is obtained. The $\mathrm{p} a_{\mathrm{y}}$. value at the point where half the estimated amount of weak acid is neutraiized, is then used as the estimate for the dissociation constant of the weak acid.

These initial estimates, the pa $a_{H}$ vs. $\mathrm{ml}$ data and eqns. (4)-(10) are used to calculate the coefficients of the normal equations for the corrections of the estimated parameters. These normal equations are solved by calculating the inverse matrix of the coefficients of the normal equations. Then an iterative procedure is followed to improve the calculated parameters. To obtain satisfactory convergence the final estimates are calculated by applying the calculated correction only partially. The fraction of the correction to be applied is found as described by Wentworth [8].

\section{RESULTS AND DISCUSSION}

The results of the computerized titrations and calculations for various mixtures of a strong and a weak acid in different concentration ratios are given in Table 2. The method was also applied to mixtures of an excess of hydrochioric acid and a weat base; in this case the computer output was the concentration of the free hydrochloric acid and the protonated base in the mixture. The results are presented in Table 3 , where the comparison of results 
TABLE 2

Computerized titrations of mixtures of a strong and a weak acid

\begin{tabular}{|c|c|c|c|c|c|c|c|c|}
\hline Sample & $\begin{array}{l}\text { Compound } \\
1\end{array}$ & $\begin{array}{l}\text { Added } \\
\left(-10^{-3} \mathrm{M}\right)\end{array}$ & $\begin{array}{l}\text { Found } \\
\left(\cdot 10^{-3} \mathrm{M}\right)\end{array}$ & $\begin{array}{l}\text { Error } \\
\text { (\%) }\end{array}$ & $\begin{array}{l}\text { Compound } \\
2\end{array}$ & $\begin{array}{l}\text { Added } \\
\left(-10^{-3} \mathrm{M}\right)\end{array}$ & $\begin{array}{l}\text { Found } \\
\left(\cdot 10^{-3} M\right)\end{array}$ & $\begin{array}{l}\text { Error } \\
(c 0)\end{array}$ \\
\hline 1 & HC! & 4.072 & 4.051 & -0.5 & $\mathrm{CH}_{3} \mathrm{COOH}$ & 4.324 & 4.357 & +0.7 \\
\hline 2 & & 8.114 & 8.087 & -0.7 & & 8.648 & 8.697 & +0.6 \\
\hline 3 & & 4.072 & 4.032 & -1.0 & & 8.618 & 8.657 & +0.1 \\
\hline 4 & & 2.036 & 2.020 & -0.8 & & 2.162 & 2.196 & +1.5 \\
\hline 5 & & 2.036 & 2.043 & +0.3 & & 4.324 & -1.330 & $\div 0.1$ \\
\hline 6 & & 4.072 & 4.022 & -1.2 & & 2.162 & 2.258 & +4.4 \\
\hline 7 & & 2.036 & 2.022 & -0.7 & & 8.645 & 8.577 & -0.8 \\
\hline $\mathbf{S}$ & & 8.114 & 8.101 & -0.5 & & 2.162 & 2.144 & -0.8 \\
\hline 9 & & 10.180 & 10.030 & -1.5 & & 1.081 & 1.257 & +16.3 \\
\hline 10 & & 1.018 & 1.435 & +40.9 & & 10.810 & 10.810 & +0.3 \\
\hline 11 & & 2.036 & 2.19 & $\div 7.6$ & & 10.810 & 10.640 & -1.6 \\
\hline 12 & & 10.180 & 10.220 & +0.4 & & 2.162 & 2.168 & +0.3 \\
\hline 13 & & 10.180 & 10.210 & +0.3 & & 2.162 & 2.126 & -1.7 \\
\hline 14 & $\mathrm{H}_{2} \mathrm{SO}_{4}$ (1) & 5.025 & 5.086 & +1.2 & $\mathrm{H}_{2} \mathrm{SO}_{4}(2)$ & 5.025 & 4.983 & -0.8 \\
\hline 15 & & 2.010 & 2.062 & +2.6 & & 2.010 & 1.999 & -0.5 \\
\hline 16 & & 1.507 & 1.525 & +1.2 & & 1.507 & 1.500 & -0.5 \\
\hline 17 & & 1.005 & 1.019 & $\div 1.4$ & & 1.005 & 0.999 & -0.6 \\
\hline 18 & (1) $+\mathrm{HCl}$ & 14.798 & 14.750 & -0.3 & $\mathrm{H}_{2} \mathrm{SO}_{4}(2)$ & 5.025 & $4.953^{\circ}$ & -1.4 \\
\hline 19 & (1) $+\mathrm{HCl}$ & 11.185 & 11.180 & -0.0 & & 1.005 & 0.997 & -0.8 \\
\hline 20 & (1) $\div \mathrm{HCl}$ & 10.154 & 10.140 & -0.1 & & 2.010 & 1.994 & -0.8 \\
\hline 21 & (1) & 5.025 & 5.062 & +0.7 & & 5.025 & 4.980 & -0.9 \\
\hline $\begin{array}{l}22 \\
23\end{array}$ & $\mathrm{HCl}$ & $\begin{array}{l}3.383 \\
4.060\end{array}$ & $\begin{array}{l}3.388 \\
4.000\end{array}$ & $\begin{array}{l}+0.1 \\
-1.5\end{array}$ & m-Cresol & $\begin{array}{l}2.938 \\
3.525\end{array}$ & $\begin{array}{l}2.976 \\
3.514\end{array}$ & $\begin{array}{l}+1.3 \\
-0.3\end{array}$ \\
\hline 24 & $\mathrm{HCl}$ & 8.120 & 8.097 & -0.3 & $\mathrm{NH}_{4} \mathrm{Cl}$ & 10.290 & 10.280 & -0.1 \\
\hline 25 & & 4.060 & 4.040 & -0.5 & & 4.116 & 4.133 & +0.4 \\
\hline 26 & & 2.030 & 2.021 & -0.4 & & i0.290 & 10.260 & -0.3 \\
\hline 27 & & 10.150 & 10.110 & -0.4 & & 4.116 & 4.170 & $\div 1.3$ \\
\hline 28 & & 4.060 & 3.997 & -1.5 & & 10.290 & 10.350 & +0.6 \\
\hline 29 & & 8.120 & 7.984 & -1.7 & & 10.290 & 10.360 & +0.7 \\
\hline
\end{tabular}

and the amount added for $\mathrm{HCl}$ were recalculated on the basis of total hydrochloric acid.

Figure 2 demonstrates that the computer method resolves mixtures even when inspection of the titration curve does not indicate that two components are present.

As can be seen from Tables 2 and 3 , the method works well even for quite strong 'weak' acids like hydrogensulphats and protonated urea, and no problems arise with very weak acids such as $m$-cresol and ammonium ion. Differences in charge type of the acid do not greatly affect the accuracy of the titrations, as is shown by the results for hydrogensulphate and ammonium ion. 
TABLE 3

Computerized titrations of mixtures of an excess of hydrochloric acid and a veak base

\begin{tabular}{|c|c|c|c|c|c|c|c|}
\hline Sample & $\begin{array}{l}\mathrm{HCl} \\
\text { added } \\
\left(\cdot 10^{-3} \mathrm{MI}\right)\end{array}$ & $\begin{array}{l}\mathrm{jiCi} \\
\text { found } \\
\left(-10^{-3} \mathrm{A1}\right)\end{array}$ & $\begin{array}{l}\text { Error } \\
(S)\end{array}$ & $\begin{array}{l}\text { Compound } \\
2\end{array}$ & $\begin{array}{l}\text { Added } \\
\left(\cdot 10^{-1} \mathrm{~N}\right)\end{array}$ & $\begin{array}{l}\text { Found } \\
\left(-10^{-3} \mathrm{M}\right)\end{array}$ & $\begin{array}{l}\text { Error } \\
(\mathscr{c}) j\end{array}$ \\
\hline $\begin{array}{l}1 \\
2\end{array}$ & $\begin{array}{l}10.150 \\
10.150\end{array}$ & $\begin{array}{l}10.170 \\
10.152\end{array}$ & $\begin{array}{l}\div 0.2 \\
+0.0\end{array}$ & Urea & $\begin{array}{l}4.000 \\
4.000\end{array}$ & $\begin{array}{l}3.982 \\
3.985\end{array}$ & $\begin{array}{l}-0.5 \\
-0.4\end{array}$ \\
\hline 3 & 10.150 & 10.112 & -0.4 & & \pm .000 & 3.987 & -0.3 \\
\hline$\frac{4}{5}$ & $\begin{array}{l}14.210 \\
14.210\end{array}$ & $\begin{array}{l}14.120 \\
1 \div .162\end{array}$ & $\begin{array}{l}-0.6 \\
-0.3\end{array}$ & $\mathrm{CH}, \mathrm{COONa}$ & $\begin{array}{l}10.000 \\
10.000\end{array}$ & $\begin{array}{l}10.050 \\
10.040\end{array}$ & $\begin{array}{l}+0.6 \\
+0.4\end{array}$ \\
\hline 6 & 10.150 & 9.953 & -1.9 & Tris & 6.000 & 5.914 & -1.4 \\
\hline 7 & 10.150 & 9.948 & -2.0 & & 6.000 & 5.952 & -0.8 \\
\hline
\end{tabular}

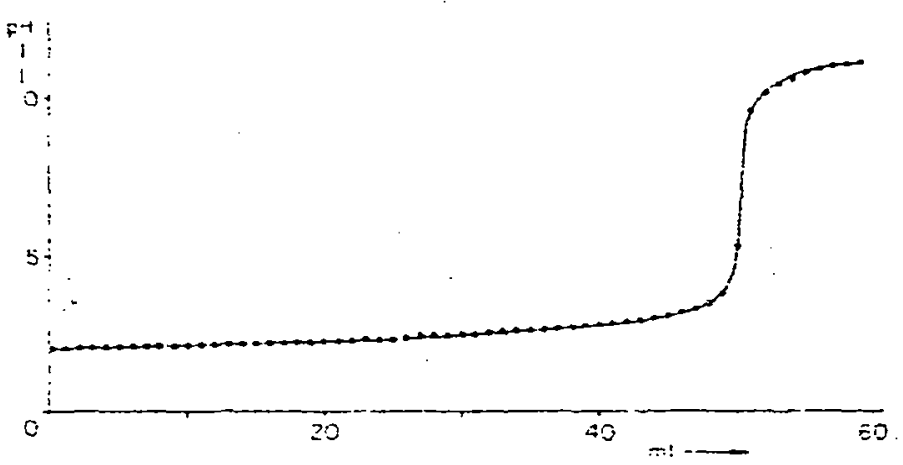

Fig. 2. Titration of a rnixture of $0.5075 \mathrm{mmol}$ of $\mathrm{HCl}$ and $0.200 \mathrm{mmol}$ of urea in $50 \mathrm{ml}$ c. $1 \mathrm{M} \mathrm{KCl} \mathrm{with} 0.100 \mathrm{M}$ sodium hydroxide.

The calculations involved in a 50-point titration curve take about $4 \mathrm{~min}$, which shows clearly the potentialities of the Wentworth approach in the clesign of computerized analytical methods for routine applications.

The activity coefficient of the acetate ion was used in all calculations for the conjugated base of the weak acid. Clearly, this is not correct, but varying this value showed that its influence was small, and it is questionable that taking this activity coefricient as a fourth parameter would improye the results significantly.

The $a_{H^{*}}$ measurements during the titration must be accurate to $\pm 0.02 \mathrm{pH}$ unit. This implies great care in the calibration and handling of the glass electrode set and in the preparation of the $\mathrm{p} a_{\mathrm{H}}$ - stanciards. Separate calibraIjon constants had to be deternined for the regions $p o_{i} \because<3,3-8$ and $>8$, in order to obtain this accuracy over the vihole titration range. The sodium hydroxide titnnt must be carbonate-frce, otherwise poor results are obtined, 
indicated by slow convergence in the calculations.

The method described for the determination of the initial estimates or the parameters $C_{\mathrm{HX}}, C_{\mathrm{HY}}$ and $K_{\mathrm{HY}}$ does not function properly for mixtures with weak acids of $p K_{a}<3$. This is because the dissociation of these acids at the start of the titration cannot be neglected. In such cases the initial estimates had to be provided manually.

The author thanks W. Tjerkstra, A. J. B. van Boxtel and A. Elling for their valuable help, Prof. Dr. Ir. E. A. M. F. Dahmen for his interest, and B. Verbeeten-v. Hettema for preparing the manuscript.

\section{REFEPENCES}

1 C. McCallum and D. Midgley, And. Chim. Acta, 78 (1975) 171.

2 L. Meites and D. M. Barry, Talanta, 20 (1973) 1173.

3 B. H. Campbell and L. Meites, Talanta, 21 (1974) 393.

4 D. M. Barry, L. Meites and B. H. Campbell, Anal. Chim. Acta, 69 (1974) 143.

5 D. M. Barry and L. Meites, Anal. Chim. Acta, 68 (1974) 435.

6 F. Ingman, A Johansson, S. Johansson and R. Karisson, Anal. Chim. Acta, 64 (1973) 113.

7 M. Bos, Anal. Chim. Acta, 81 (1976) 21.

8 W. E. Wentworth, J. Chem. Educ., 42 (1965) 96.

9 H. S. Harned and B. B. Owen. The Physical Chemistry of Electrolytic Solutions, Reinhold, New York, 1964, pp. 591, 638, $752,748$.

10 H. S. Hamed and R. W. Ehlers, J. Am. Chem. Soc., 55 (1933) 652.

1 I. H. S. Hamed and F. C. Hickey, J. Am. Chem. Soc., 59 (1937) 2303.

12 II S: Hamed and M. A. Cook, J. Am. Chem. Soc., 59 (1937) 1290. 